\title{
Políticas curriculares no Rio Grande do Sul (2009-2018): do triunfo neoliberal à captura do ensino de Filosofia
}

\author{
Curriculum policies in Rio Grande do Sul (2009-2018): from the neoliberal triumph \\ to the capture of Philosophy teaching
}

\author{
Bruno Nunes Batista \\ Professor Doutor na Universidade Federal de Pelotas, Pelotas, Rio Grande do Sul, Brasil. \\ brunonunes.86@hotmail.com - https://orcid.org/0000-0002-3862-1465
}

\section{Daniel Schiochett}

Professor Doutor na Universidade do Sul de Santa Catarina, Tubarão, Santa Catarina, Brasil. danielschiochett@gmail.com - https://orcid.org/0000-0003-4498-8586

Recebido em 04 de junho de 2020

Aprovado em 08 de julho de 2020

Publicado em 30 de julho de 2020

RESUMO: Neste texto, prospectado sob a égide dos estudos foucaultianos, com enfoque maior no campo da Educação, reflete-se sobre currículo e ensino de Filosofia com base em três frentes de trabalho: 1) a problematização do neoliberalismo empreendida por Michel Foucault em 1979; 2) as conexões entre neoliberalismo e Educação; 3) os desdobramentos dessas relações de poder e saber no ensino da Filosofia, por intermédio da análise discursiva de parâmetros curriculares dispostos no Estado do Rio Grande do Sul entre 2009 a 2018. Do interior desses movimentos, conclui-se que o projeto neoliberal vem flanqueando os currículos da Filosofia escolar ao longo da última década nesse Estado com sucessivas investidas, ora colocando-a a serviço da cultura do empreendedorismo, ora eliminando-a do currículo. Palavras-chave: Ensino de Filosofia; Michel Foucault; Discurso; Arquivo; Currículo.

ABSTRACT: In this text, prospected under the aegis of Foucauldian studies, with a greater focus on the field of Education, it is reflected on Philosophy curriculum and teaching based on three fronts of work: 1) the problematization of neoliberalism undertaken by Michel Foucault in 1979; 2) the connections between neoliberalism and Education; 3) the unfolding of these relations of power and knowledge in the teaching of Philosophy, through the discursive analysis of curricular parameters arranged in the State of Rio Grande do Sul between 2009 and 2018. From within these movements, it is concluded that the neoliberal project has been flanking the curricula of school philosophy over the last decade in that state with successive attacks, sometimes placing it at the service of the culture of entrepreneurship, sometimes eliminating it from the curriculum. Keywords: Philosophy teaching; Michel Foucault; Speech; Archive; Curriculum.

\section{Introdução}

Talvez uma das frases mais citadas na história da Filosofia Política tenha sido aquela apregoada por Karl Marx, segundo a qual a Filosofia teria se especializado em compreender o 
mundo, ao invés de transformá-lo. E, de fato, para compreender a emergência da sociedade industrial, o processo de mais-valia, a obsolescência planejada, a alienação do trabalho e a extensão do modelo da fábrica às múltiplas instâncias da sociedade, a passagem pelos textos clássicos do materialismo histórico-dialético é obrigatória. Porém, na contemporaneidade, e pensando no âmbito do ensino de Filosofia, essa seria a única parada, ou não? Afinal, sabemos como a reestruturação operada pela acumulação flexível nas últimas décadas vem transformando as maneiras como vivemos e experimentamos a díade espaço-tempo; com a automação dos processos produtivos e a introdução das novas tecnologias da informação e comunicação no bojo das relações sociais, não mais uma superprodução será sinônimo de lucratividade, de forma que os valores carreados atualmente pelo capitalismo estão mais próximos aos ideários do empreendedorismo, da competitividade, da inovação, do consumo constante e, é claro, do investimento em capital humano.

Segundo a hipótese que gostaríamos de desenvolver neste texto, uma problematização das conexões entre a educação, o ensino de Filosofia e o capitalismo contemporâneo supõe perspectivar outras grades de inteligibilidade. Dentre essas grades, o aporte dos estudos foucaultianos, no que concerne às relações entre subjetividade e neoliberalismo, são profícuas para conjecturarmos a educação filosófica de outro modo.

Em termos de perspectiva de trabalho, nosso enfoque é o ensino de Filosofia. Assim, iniciamos a analítica discutindo as correias transmissoras conceituais do pensamento de Michel Foucault, apresentando o percurso que ele desenvolveu até chegar nas problematizações acerca do neoliberalismo (FOUCAULT, 2008). Feito isso, aproximamo-nos do ensino de Filosofia, elencando para debate a maneira como esse vem sendo tratado nos parâmetros curriculares do ensino oficializados, nos últimos dez anos, no Estado do Rio Grande do Sul. Por intermédio dessa grade, objetivamos estabelecer, ao final, um olhar de como a Filosofia escolar é pensada na contemporaneidade e a que relações de poder/saber ela estaria subordinada.

\section{Foucault: dos corpos dóceis às subjetividades flexíveis}

A frente de trabalho percorrida por Foucault, nos primeiros anos da década de 1970, debruça-se sobre a emergência da sociedade disciplinar, evento que se instaura nos canteiros das fábricas, dos quarteis, dos hospícios, dos hospitais e das escolas entre os séculos XVIII e XIX e que são bastante aproximáveis aos quadros descritos pelos textos marxistas sobre as indústrias e as cidades operárias. O mote, por exemplo, de Vigiar e Punir, livro lançado na França, em 1975, é que tanto para o aumento da produtividade quanto para a construção da liberdade do lluminismo, foi necessário que inúmeras instituições fossem postas em operação, com o intuito de fabricar corpos dóceis (FOUCAULT, 1987a). Através das descrições levadas a cabo por Foucault (1987a), foi possível identificarmos uma semelhança espantosa entre locais aparentemente tão díspares, como uma escola secundária e uma prisão. De um lugar a outro, ao longo de uma vida, os indivíduos foram sendo aos poucos subjetivados por um regime de poder e saber, próprio à industrialização das técnicas tayloristas/fordistas e à constituição do Estado Moderno.

Entretanto, em diversos momentos do século XX, alterações em curso no âmbito da economia, do capital produtivo, do Estado e da política mexeram com as bases daqueles poderes hegemônicos. Como explica Hobsbawm (1995), fatores como o 1) fracasso do liberalismo 
clássico e os ideários da mão invisível do capital, 2) o esgotamento do Estado de Bem-Estar Social, 3) os perigos dos regimes totalitários, 4) a modernização tecnológica, 5) a inédita concorrência das nações emergentes e, não menos importante, 6) a transição demográfica em curso na maioria das nações desenvolvidas tornaram difíceis os gestos fáceis e, em algum ponto do século passado, a extensão do fordismo à vida cotidiana nas suas diversas práticas deu um sinal de esgotamento até então inimaginável, cujos efeitos assustam-nos até hoje. Eis que, no crepúsculo do século XX, o trabalhador alienado/repetitivo de Marx e o corpo dócil/ disciplinado de Foucault não são mais úteis; são substituíveis e descartáveis.

Do ponto de vista da empregabilidade, as consequências são imediatamente identificáveis: precarização, terceirização, vínculos temporários, automação dos postos de trabalho e desemprego estrutural são algumas das características que nos vêm rapidamente à mente. Já no que se refere à razão de Estado e às reformas econômicas, surge a concepção de que estamos vivendo sob a égide do neoliberalismo. Esse comumente é apresentado como um retorno ao laissez-faire de Adam Smith, simbolizado ideologicamente pelo Consenso de Washington, representado em termos políticos nos governos de Thatcher, Reagan e Pinochet e que objetiva a instauração do Estado Mínimo, com a posterior privatização de todas as suas instituições.

Foucault (2008) analisa o neoliberalismo de maneira diferente. A imbricação das suas duas perspectivas filosóficas de trabalho - a arqueologia e a genealogia - constituem-se em potentes métodos de compreensão e diagnóstico do presente, que, se por um lado não prescrevem modelos de intervenção na realidade, por um outro lado servem-nos como caminhos para praticar atos individuais de resistência. Herdeira de Kant (1980), a crítica foucaultiana volta-se para o próprio conhecimento, perscrutando as condições de possibilidade para que um determinado saber tenha tomado forma. Leitor atento de Nietzsche (1998), assume que, ao contrário de Bacon, o poder vem antes do saber, enformando-o. Foi justamente essa pegada filosófica que o fez perceber um certo esgotamento do poder disciplinar, que já não se conformava com os processos em curso da economia e da política.

Nas aulas de O Nascimento da Biopolítica, Foucault (2008) identifica a emergência da grade neoliberal já em meados dos anos 1940; naqueles tempos, os economistas não advogariam a separação do Estado da economia de mercado, mas sim uma subordinação inédita dele a ela, com novas propostas, novas subjetivações e novas relações de poder. A serviço da economia de mercado, um Estado neoliberal não se ausenta, e sim apresenta-se ao tribunal econômico, funcionando ora como uma empresa com regras de eficácia e eficiência, ora como juiz de jogos competitivos, estabelecendo leis e normas (FOUCAULT, 2008). Já no que cabe ao controle das suas instituições, o Estado azeita as relações de mercado a partir da promoção de subjetividades flexíveis, competitivas e empreendedoras, haja visto que expoentes do neoliberalismo ,como Von Mises, Friedman e Hayek sabem que não há espaço para todos no capitalismo e que alguns vão vencer e a maioria perderá (VEIGA-NETO, 2000; DARDOT, LAVAL, 2016; AQUINO, 2019).

Ao longo desse período, a discussão entre a ideia de um Estado mínimo ou máximo acabou por transformar-se em um falso dilema, pois, no bojo do neoliberalismo, essa 
dicotomia sequer existiu. Isso porque quando levamos em conta que a ação estatal põe-se a serviço do mercado, ela tem uma mão leve e pesada (BATISTA, 2019). Leve no sentido de uma intervenção silenciosa, para consertar aquilo que pode obstaculizar o livre exercício da atividade econômica. Pesada, porque instaura órgãos classificadores, estatísticos e avaliativos, fazendo uso do maior número de dados, de fontes, de conclusões científicas e de inventários demográficos, a fim de eficiente e eficazmente governar a população em prol de uma competição ordenada. Assim, faz com que o Estado crie as condições para que todos possam competir e tornar-se empresários de si mesmos (BATISTA, 2019). Nessa sociedade empresarial, o destaque é dado à noção de um jogo, no qual todos são forçados a participar e alguns vão ganhar e outros vão perder.

\section{Educação: a "menina dos olhos" do neoliberalismo}

Ao analisarmos o contraste que se forma entre as subjetividades requeridas pela fábrica, força-motriz do capitalismo industrial-fordista, e as subjetividades requeridas pela empresa, uma das principais âncoras do pensamento neoliberal, o desdobramento mais evidente dessa mudança de ênfase dá-se o terreno da escola. No caso da escolarização formal, os efeitos são sensíveis. Produto de um a priori histórico, Foucault (1987a) foi brilhante em identificar como a docilização dos corpos, promovida pelas disciplinares escolares, estavam concatenadas aos pressupostos da industrialização. Substanciada pela Pedagogia tradicional, em que o aluno era visto como uma tábula rasa em que seriam inseridos dados conteúdos, tratava-se da construção de uma subjetividade para a vida inteira, um projeto de vida estável cuja escolha de uma profissão ofereceria garantias futuras, ainda que às custas de privação do presente, planejamento extremo e uma disciplina, muitas vezes, de rebanho. Ora, essa segurança proporcionada por um trabalho duro é justamente aquilo que a contemporaneidade não pode mais oferecer, colocando-nos, como perspicazmente detalhou Sennet (2008), à deriva. E a escola, que apesar de antes ser um ponto indigesto e postergador de satisfações, mas que servia como escada para uma elevação de modos de vida, entra em uma crise profunda, por diversos fatores. Por um lado, já não é mais detentora exclusiva das informações, que estão disponíveis abundantemente nas plataformas digitais existentes; garantidora de ascensão econômica e social, hoje não passa de um lugar que garante, no máximo, condições de empregabilidade (BECK, 2010).

No entanto, a crise das instituições escolares não significaria, paradoxalmente, anunciar o seu fim. Nessa perspectiva alinhavam-se, aliás, as interlocuções entre educação e neoliberalismo. A racionalidade neoliberal atua em imanência com a realidade, ou seja, ela tanto é corolário das condições econômicas e estruturais do capitalismo contemporâneo quanto constrói disposições que intensificam esse. Levando em conta que o Estado neoliberal jamais seria mínimo, mas tampouco semelhante ao Estado de Bem-Estar Social, o que se coloca em um curso é uma terceira via (DARDOT; LAVAL, 2016), cujo fito é a elaboração de estratégias que podem tornar o Estado mais empresariado e, por fim, servir da melhor forma possível ao mercado.

Tal padrão de conduta insere-se a educação com o intento de formar o microempresário, que investe sobre si mesmo, toma decisões, assume riscos e realiza cálculos, prognósticos e planejamentos. Para tanto, o empreendedor ideal efetua um trabalho continuado sobre si 
mesmo, potencializando seu capital humano de modo que seja mais ativo, atraente e eficiente (FOUCAULT, 2008). Ao desenvolver estratégias competitivas, de modo que possa inclusive vender-se no jogo da economia de mercado, ele efetua uma ascese, de forma a comparar o seu desempenho com uma imagem de sucesso e criatividade nos negócios (COSTA, 2009). Por outro lado, o empreendedor tem plena noção dos riscos que corre nesse jogo, o que o faz educar-se permanentemente, seja por meio da escolarização formal, seja com o auxílio de coachs, managers, experts e outros "condutores de boas práticas". Nas palavas de Hardt (2000), a subjetividade empreendedora é artificial ou até mesmo plástica, pois ao exigir do trabalhador que faça seguidas formações continuadas, o que interessa é que o indivíduo qualifique-se para sucessivos processos de desaprendizagem.

Se o projeto do empreendedor ideal tem como correias transmissoras tais atitudes e procedimentos, talvez fique um pouco mais fácil identificarmos como isso rebate e ressoa na educação, com enfoque no âmbito da escola, da Pedagogia e do currículo. Nos currículos oficiais do Ministério da Educação, do Estado e dos municípios, assim como também nos parâmetros da Rede Privada de Ensino, percebe-se um ensino balizado pela formação de competências e habilidades, a fim de que o aluno seja capaz de resolver problemas de ordens variadas. Com os conteúdos em segundo plano, consegue-se observar que a importância dá-se mais para as condições advindas do cotidiano do estudante, que devem servir como combustível para ele pensar nas melhores soluções para o seu lugar. As pedagogias de projetos (nas quais o aluno escolhe o que estudar), as metodologias ativas (em que se colocam os estudantes perante jogos simuladores da realidade) e a interdisciplinaridade (que incentiva os trabalhos em equipe toyotistas) são outros bons exemplos do atravessamento neoliberal nos arranjos escolares (BATISTA, 2019). De forma semelhante, já está em curso um deslocamento do papel atribuído ao docente, que passaria de transmissor de conteúdos a gestor de competências, cabendo-Ihe orientar seus alunos para serem fortes em situações arriscadas e problemáticas. Com efeito, a "matéria" a ser ensinada passa a ser validada pela possibilidade de guiar os alunos nos seus projetos de vida para que eles possam, por meio dos conteúdos, alçarem-se a empresários de si mesmos.

É por esses motivos que, no interior do estatuto de verdade neoliberal, não podemos falar da "morte" do Estado nem, muito menos, do fim da escola. Há, sim, uma modificação intensa das suas atribuições, que vêm sendo postas em operação nos últimos anos, com uma velocidade que impressiona e com uma facilidade, por sua vez, não menos chocante. Nessa padronização de subjetividade, pautada pela idealização de um sujeito que estende os cálculos econômicos a todas as instâncias da vida e da condição humana, os valores da liberdade e da autonomia até podem atrair-nos. Porém, é preciso saber o que vem a reboque desses ideários. Já a educação contemporânea, que tanto esforça-se por rebaixar a Pedagogia tradicional a uma condição de anacronismo e, principalmente, autoritarismo, incorre em um problema semelhante, que é justamente o de não perceber como pode ser subserviente às relações de poder e de saber hegemônicas do neoliberalismo.

\section{Arquivo e discurso: trabalhando com Foucault}

Trabalhar com Foucault pressupõe de imediato que seja definido um corpus de análise, em que os discursos materializam-se e assumem uma monumentalidade. Às vezes dispersos, em outros momentos rarefeitos, a massa de ditos e escritos expressada em uma certa época e de um certo modo constitui-se, quando problematizada em meio a relações de 
poder e saber, em um arquivo, noção central da arqueologia e da genealogia foucaultiana. Como explica Aquino (2019), essa acepção de arquivo não se assemelharia às modalidades comumente enunciadas, que o expressam em termos de patrimônio físico e/ou memória coletiva. Em outro prisma, o arquivo aparece aqui como um conjunto de discursos que foram pronunciados e que, aparentemente esquecidos, ainda continuam a delimitar o que pode ser dito e escrito sobre um dado tema, como se fosse uma lei. Sendo assim, o arquivo é estatuto de verdade e módulo de verificação dela, dispondo o certo e o errado, o normal e o anormal (FOUCAULT, 2000); é, simultaneamente, conservador e produtor, pois é dele que parte a linguagem em seus mais variados comandos (DERRIDA, 2001). Não por acaso, ele funciona como um conjunto total dos ditos e escritos que foram pronunciados ao longo de uma determinada época e que continuam a exercer funções contemporaneamente, transformando enunciados e exortando a formação de novos conceitos alinhados a "regras de formação, de existência, de coexistência, a sistemas de funcionamento" (FOUCAULT, 2000, p. 146).

É por isso que, ao operarmos com a noção de arquivo, uma investigação desse timbre se torce sobre o próprio pensamento acumulado ao longo de uma faixa discursiva, possibilitando "determinar as condições de sua existência, de fixar da maneira mais justa os seus limites, de estabelecer suas correlações com os outros enunciados aos quais ele pode estar ligado, de mostrar que outras formas de enunciação ele exclui" (FOUCAULT, 2000, p. 93).

Com essa explicação assentada, valeria agora descrever com quais documentos e de que jeito a aproximação teórica-metodológica será feita.

Primeiramente, para operarmos com as teorizações foucaultianas dispostas junto ao problema elencado a respeito do ensino da Filosofia, percorremos os parâmetros curriculares oficiais do Estado Rio Grande do Sul na última década. Tal escolha não é mero acidente, nem se deu de modo aleatório. Do ano de 2009 até a data de escrita deste texto, esse Estado já elaborou e colocou em práticas nada menos do que quatro propostas de reforma curricular; aqui, podemos erguntar: houveram rupturas, permanências, continuidades? Ou as coisas vêm sendo mudadas para permanecerem as mesmas? Por outro lado, no período em tela, a Administração Pública Estadual foi governada por Yeda Crusius (2007-2011), filiada ao Partido da Social Democracia Brasileira (PSDB) e com representação ideológica mais alinhada à direita; Tarso Genro (2011-2015), pertencente ao Partido dos Trabalhadores (PT), notoriamente um movimento de esquerda; José Ivo Sartori (2015-2019), do Partido do Movimento Democrático Brasileiro (MDB) e, que nas últimas décadas, vem se destacando como uma representação de "centro"; e, em vigência, a gestão do Governador Eduardo Leite, materializando um retorno do PSB ao comando do Estado e que parece possuir, como plataforma de Governo, uma inspiração francamente neoliberal, com um verniz progressista acentuado.

Dessa faixa temporal, o primeiro referencial curricular, publicado em 2009, ficou conhecido como "Lições do Rio Grande". Partindo de um cenário descrito na introdução do documento como desolador e precário, a então Secretaria de Educação argumentaria que não bastariam apenas investimentos no patrimônio das escolas se, em contrapartida, "o ensino continuar a ser desenvolvido apenas com quadro negro, giz e livro didático" 
(ABREU, 2009, p. 7). Esse e outros motes anunciavam uma transformação da grade curricular com viés interdisciplinar, baseada na ideia de competências e habilidades.

$\mathrm{Na}$ gestão seguinte, de Tarso Genro, procurou-se em, 2011, substituir a reforma anterior pela chamada "Proposta pedagógica para o Ensino Médio Politécnico e Educação Profissional integrada ao Ensino Médio". Saem as competências e habilidades e entra a concepção do trabalho como princípio educativo, com inspiração notadamente do materialismo histórico-dialético e tendo como intelectuais orgânicos Marx, Engels e Gramsci. Ancorado nos conceitos de politecnia e omnilateralidade, o centro da reforma aqui desencadeada seria propiciar aos estudantes uma formação integral (científica, artística, humana, tecnológica), sem abdicar, no entanto, da preparação para o mundo do trabalho.

Uma nova ruptura, porém, surgiria no horizonte gaúcho. Publicada em 2016 como "Reestruturação curricular Ensino Fundamental e Médio", no segundo ano de mandato de Ivo Sartori, tal proposta anunciava na sua apresentação o intento de pensar na integralidade do ser, na qual os horizontes intelectuais, emocionais, sociais e culturais passariam a ser os grandes desafios da escola no século XXI. Com lastro legal, conforme o texto, na Constituição Federal de 1988 e na LDBEN 9394/96, a concepção politécnica seria substituída por princípios já alavancados pelo "Lições do Rio Grande", isto é, a de grades curriculares formadas por competências e habilidades. Nessa linha de raciocínio, elas contemplariam "metodologias voltadas para o estudo das diferentes trajetórias planejadas e vivenciadas pelos educadores, a fim de orientar o processo de ensino e de aprendizagem em função de objetivos ou fins educativos" (ESTADO DO RIO GRANDE DO SUL, 2016, p. 9).

Pouco mais de dois anos depois, entretanto, uma outra reestruturação emergiria no horizonte educacional gaúcho, estando ela em vigência. No final do mandato de Sartori, em 2018, o "Referencial curricular gaúcho" era compartilhado com a comunidade escolar na mesma esteira da Base Nacional Comum Curricular (BRASIL, 2018), por consequência ancorado em dez macrocompetências essenciais, que objetivam proporcionar aos discentes saberes de ordem cognitiva, comunicativa, pessoal e social. Essa reestruturação teria sido construída de forma democrática e colaborativa, refletindo o desejo de uma educação de qualidade para todos (ESTADO DO RIO GRANDE DO SUL, 2018, p. 16).

Com esse arquivo de estruturas curriculares agora disposto, podemos problematizar esse grupo de documentos nas suas regras internas, com suas estratégias de formação. $\mathrm{Na}$ Arqueologia do saber, Foucault (1987b) mostrou-nos que a sua análise de discurso não se ancora na guarida da ideologia, fazendo um movimento de encontrar o que está "por trás" de uma formação discursiva, invisivelmente. Tampouco se faz uma teoria a priori que serve como verificação de verdade e régua de medida do que se está pesquisando. Dito de outro modo, faz-se um esforço de abdicar dos juízos de valor para, perante certos arquivos, compreender suas regras de formação e existência e, assim, descrever suas superfícies de emergência, que seriam as áreas onde o discurso aparece materialmente.

Isso exposto, a análise discursiva na próxima seção transcorre na esteira das seguintes perguntas: 1) Quais são as similaridades e diferenças entre os currículos 
elencados? 2) Que elementos pedagógicos são rebaixados e erguidos? 3 ) Que tipificação de sujeito esses documentos pretendem fabricar? 4) Como o ensino de Filosofia emerge nesse contexto?

\section{Inventário dos referenciais gaúchos (e uma Filosofia que se apaga)}

Ao traçarmos um diagrama geral dos documentos escrutinizados, é preciso destacar que as normatizes curriculares em tela mais assemelham-se do que se diferem; apontam antes de tudo um único caminho, que supostamente balizaria um projeto social; ancoram-se numa mesma matriz pedagógica, que ressoa por todas as suas páginas; se contrastam, é muito mais em forma do que em conteúdo; têm em si, lastimavelmente, uma tendência que se cristaliza: o ensino de Filosofia num papel coadjuvante, quando não inexistente e/ou numa linha crepuscular.

Em primeiro lugar, os quatro parâmetros curriculares colocam que foram construídos coletivamente, por intermédio de um movimento democrático que transitou do chão da escola aos especialistas educacionais. Tal percurso ouviu professores e profissionais da Educação, circulando por diversas cidades do Estado do Rio Grande do Sul; deu voz a atores historicamente silenciados, que costumeiramente eram excluídos dos processos de decisão curriculares. Essa mesma rota também teve um ponto de parada no interior das Universidades, em que as pesquisas desenvolvidas trouxeram evidências científicas de como andam e como devem andar os processos de ensino e de aprendizagem no século XXI.

Uma outra característica presente em todas as propostas e que, de forma semelhante, aparece na introdução desses textos, é a absoluta urgência com a qual eles se postam perante a educação gaúcha, isto é, como se estivessem diante de uma terra arrasada. Consequentemente, das "Lições do Rio Grande" em 2009, ao "Referencial Curricular Gaúcho", de 2018, procurava-se responder aos seguintes desafios: a defasagem de aprendizagem, as altas taxas de evasão, os índices alarmantes de reprovação e a precarização estrutural.

Os três primeiros itens se desdobram na conclusão de que a Rede Pública de Ensino não vem respondendo aos anseios dos estudantes e, mais do que isso, castiga-os de formas variadas por questões cuja responsabilidade não é deles. Com a ajuda da Estatística, as propostas provam que um número pequeno de alunos está matriculado em séries correspondentes à sua idade, o que supõe, entre outros fatores, taxas de reprovação preocupantes e dispositivos de avaliação punitivos de formatos retrógrados. O resultado desse emaranhado é óbvio: altíssimos índices de evasão, tendo o Ensino Médio à frente desse processo.

Por outro lado, a precarização da infraestrutura das escolas é apontada, ainda que com menor ênfase. Vale ressaltar que essa defasagem teria a ver com, peremptoriamente, dois elementos de maior relevo: o atraso tecnológico e a ausência de políticas de formação continuada de professores. No que se refere ao primeiro item, os textos inventariam uma rede "parada no tempo", o que costumava ser representado pela insuficiente conexão com a Internet nos seus espaços e, igualmente, pelo número reduzido e debilitado de laboratórios de informática nas escolas. Quanto ao segundo item, o enfoque dava-se na necessidade de promover cursos de capacitação em serviço para os docentes e técnicos educacionais, de modo que eles pudessem ser inseridos com sucesso nas competências da contemporaneidade, dentre elas - e principalmente - a alfabetização na cultural digital.

O terceiro caminho adotado pelos currículos na faixa de tempo definida funciona como o outro lado da desafiante moeda já sinalizada nas características anteriores. Se, 
por um lado, o aparato administrativo e pedagógico daqueles governos defendia estar diante de uma terra arrasada educacional, não menos instigante para esses atores era defrontar-se com um espaço geográfico enervado de transformações técnicas, produtivas, econômicas e culturais. Nesse contexto, podemos identificar, no interior desses ditos e escritos, dois pontos de convergência discursiva, liderados ora pela ideia de "Século XXI", ora pela necessidade de forjar, por intermédio da escola, umsujeito com formação integral.

No que tange ao período em que nos encontramos, os documentos são categóricos em apontar algumas das características imanentes àquilo que Santos (1996) havia definido como meio técnico-científico-informacional. Trata-se, em poucas palavras, da fase do capitalismo em que a acumulação flexível dá cartas e a produção fordista, por sua vez, perde em força. Com a inserção das novas tecnologias na economia de mercado e com a gradual automação de funções antes exercidas por pessoas, estaríamos lidando com uma redefinição de funções e profissões, em que muitas seriam extintas, enquanto outras, redefinidas. Para um mundo arriscado, tenso e incerto, não poderia ser admitida uma educação aos moldes da escola moderna. É daí que podemos entender o espírito dessas disposições curriculares.

Em outra perspectiva, a formação integral emerge como uma verdade inquestionável, cuja construção transforma-se em uma questão premente para a escola gaúcha. Em três, dos quatro documentos que estamos escrutinizando, ela é explicada através da concepção de um sujeito que não é tão somente competente em termos profissionais, mas que se faz presente de modo satisfatório em condições variáveis de larga escala. Dito de outro modo, um sujeito integral atende a requisitos intelectuais elevados e dá conta por completo de questões afetivas e emocionais. Ele é solidário, resiliente, empático e criativo diante de situações novas; sabe da sua condição de cidadão e atua politicamente em prol de causas inegavelmente sensíveis, como a luta contra a desigualdade, a defesa do direito de minorias e a ação conjugada à preservação e à conservação do meio ambiente em termos sustentáveis.

O círculo das semelhanças vem fechar-se, na rede sobreposta e continuísta que se formou a partir desse cimento discursivo, com as provisões pedagógicas orientadores dos parâmetros curriculares em tela. Tais provisões são, a saber: 1) a provisão de um ensino que fosse centrado no aluno, ao invés do professor; 2 ) a provisão de instrumentos que empreendessem a mediação, e não a transmissão de conteúdos; 3 ) a provisão de metodologias ativas e participativas; 4) a provisão da interdisciplinaridade, a fim de integralizar conhecimentos de ordens diversas; 5 ) a provisão de elementos pedagógicos que aproximassem a escola do trabalho; 6 ) a provisão de um currículo operacional em termos humanísticos, culturais, tecnológicos e afetivos, constituído de saberes significativos e próximos ao cotidiano discente; e 7) a provisão de inovações tecnológicas nos processos de ensino e aprendizagem.

Mas para não dizer que não tenhamos identificado diferenças entre os currículos, uma questão merece mais do que mera identificação, e, sim, um debate especial. É o caso, finalmente, do ensino de Filosofia. Mesmo uma leitura aligeirada dos parâmetros postos em análise discursiva consegue perceber como essa área do conhecimento foi perdendo espaço, ao longo da última década, nos currículos do Estado do Rio Grande do Sul. Trata-se de um movimento gradual, certamente acompanhado de outras políticas que vêm pondo em xeque as próprias Ciências Humanas, mas que lastimavelmente sinaliza para um futuro no mínimo sombrio para essa disciplina.

$\mathrm{Na}$ esteira da Lei 11.684, de 2008, que tornava as disciplinas de Filosofia e Sociologia obrigatórias no Ensino Médio, a proposta curricular das "Lições do Rio Grande" atribuiria, no 
ano seguinte, uma centralidade digna de elogio ao ensino do saber filosófico. Ressalvadas algumas questões de timbre neoliberal, como tendo em primeiro plano a concepção de "competências e habilidades", pode-se apontar uma escrita cuidadosa no que tange à Filosofia, com indicações didático-pedagógicas que procuram ir além do senso comum educacional. Em outras palavras, é preconizado um estudo dos clássicos filosóficos que balizam os três grandes alicerces do conhecimento filosófico, isto é, o conhecimento, a ética e a estética; e esses, por sua vez, são defendidos e valorizados, colocados como indispensáveis aos alunos da Escola Básica, tendo em vista a importância que eles possuem para construir uma formação integral.

Mas é claro que, no mesmo texto que valoriza sobremaneira a Filosofia aparece, a reboque, um conjunto de prescrições pedagógicas que se concatenam aos princípios norteadores cuja caracterização já o fizemos. Conforme o pressuposto alinhavado (ESTADO DO RIO GRANDE DO SUL, 2009), reconhecer a validade da Filosofia no Ensino Médio não significa torná-la uma disciplina pedante, erudita e exageradamente focada na Lógica, tal como na Escolástica, nem tratá-la como se fosse operada no bojo de um enciclopedismo erudito de pensadores do Renascimento como Rabelais e Erasmo (DURKHEIM, 1995).

Opostamente, propõe-se um ensino filosófico que tenha como foco o desenvolvimento de competências, "e não o acúmulo de informações, buscando sempre o alinhamento dos conteúdos a serem trabalhados à vivência do educando em seus contextos culturais, éticos e sociais, o que não deve se restringir a um repertório de textos e formulações" (ESTADO DO RIO GRANDE DO SUL, 2009, p. 117). Nesse sentido, o docente deve operar a história da Filosofia e os seus clássicos mirando a construção de habilidades no âmbito da leitura, da escrita, do exercício do pensamento crítico e do melhoramento da argumentação. Ao incentivar e proporcionar ambiências para tais questionamentos, o objetivo é tornar o estudante consciente da sua cidadania e ciente dos seus direitos e deveres; sujeito, enfim, proativo, autônomo, atuante e empreendedor, o que "nos remete à competência de resolver problemas. Como apontado nos Referenciais da área, a resolução de problemas é uma maneira de levar os alunos a aprender a aprender" (ESTADO DO RIO GRANDE DO SUL, 2009, p. 122).

Entretanto, se em 2009 assistíamos à defesa de um ensino de Filosofia operante e cuja importância não se discutia, com o percorrer dos anos seguintes essa disciplina passou a não ser mais citada diretamente, deixando de receber um lugar especial nos parâmetros currículos gaúchos.

Com o Ensino Médio Politécnico de 2011, ela está diluída na área do conhecimento das Ciências Humanas e suas Tecnologias, sendo apenas representada por intermédio de alguns eixos temáticos transversais, como "direitos humanos", "cultura e artes" e "comunicação e uso de mídias". Isso é algo, no mínimo, grotesco, haja vista que o próprio solo teórico da proposta tem em filósofos como Marx e Gramsci seus principais intelectuais. Além disso, a materialidade desse currículo torna-se ainda mais decepcionante quando lembramos que, na concepção escolar construída por Gramsci (2001), intitulada de unitária e omnilateral, o estudante proveniente das classes populares receberia uma educação completa, abrangendo os saberes científicos e tecnológicos necessários não apenas ao trabalho produtivo, mas principalmente a uma vida feliz, em que as artes e a fruição coexistiriam com a transformação da realidade (NOSELLA, 1992). Ora, que currículo é esse que aponta a filosofia da educação gramsciana como arcabouço teórico ao mesmo tempo em que impõe à Filosofia uma posição subalterna?

Já na Reestruturação de 2016, cuja correia de transmissão são as competências e habilidades e o lema é o "aprender a aprender", o quadro se repete-se, dessa 
vez com a Filosofia (citada uma única vez diretamente) servindo de esteio para os seguintes conceitos estruturantes: tempo, espaço, fenômenos, trabalho, poder, dominação, relações etno-socioculturais, identidade, ética e estética. Ressaltamos que o diálogo com esses conceitos não aparece de modo exclusivo à Filosofia, mas em comum com área de Ciências Humanas e a serviço da "resolução de problemas".

Por fim, o documento em vigor "Referencial Curricular Gaúcho" ancora-se na descrição e na prescrição de políticas didáticas, pedagógicas e curriculares subjacentes ao Ensino Fundamental, em que a grade de disciplinas referente às humanidades contém apenas Geografia e História. Se esse parâmetro assumiu a incumbência de construir uma proposta própria ao Rio Grande do Sul, ele se baliza-se, porém - e amplamente -, na Base Nacional Comum Curricular do Governo Federal, em que os princípios norteadores também operam com a noção de competências. Já no que se refere ao Ensino Médio, lugar no qual esperamos encontrar a Filosofia, esse Estado parece deixar a cargo do Governo Federal expressiva parte do seu planejamento curricular. Assim, o impacto no ensino filosófico é direto: incluso na agora intitulada área das Ciências Humanas e Sociais Aplicadas, cabe a esse um papel novamente de coadjuvante, ao qual the compete ativar competências específicas, com base nos "ideais de justiça, solidariedade, autonomia, liberdade de pensamento e de escolha, a compreensão e o reconhecimento das diferenças, o respeito aos direitos humanos e à interculturalidade" (BRASIL, 2018, p. 561).

Das breves descrições empreendidas a respeito da última década curricular no Rio Grande do Sul, certamente vem à tona a lastimável perda gradual de protagonismo do ensino da Filosofia nos arranjos curriculares desse Estado. Caso conjecturarmos que a maior parte desse período esteve sob a égide de uma legislação que tornava obrigatória a Filosofia no Ensino Médio, a surpresa é maior, assim como a sensação de que só temos a lamentar. Nessa linha de raciocínio, provavelmente não será motivo algum de preocupação para os burocratas, especialistas, administradores e redatores gaúchos pensar em medidas a serem tomadas a partir da Lei 13.415 de 2017, que retirou a obrigatoriedade da disciplina de Filosofia no ensino médio das escolas brasileiras. Afinal, esse Estado vem estando na vanguarda desse dispositivo legal, preparando o terreno para a despedida de um componente curricular recém-chegado - e raramente valorizado.

\section{Para concluir}

Com a perspectiva de trabalho arrolada ao longo deste breve texto, esperamos que tenha sido possível levar a cabo um olhar sobre o ensino de Filosofia a partir das lunetas dos parâmetros curriculares do Estado do Rio Grande do Sul. Entretanto, essa correia de transmissão não procurou discutir as possibilidades de aplicar as disposições definidas nestes documentos, nem, tampouco, averiguar se elas estariam sendo aplicadas ou não no interior da sala de aula. Por intermédio de algumas noções foucaultianas, nossos objetivos predispuseram um certo distanciamento, em que a descrição dessas propostas curriculares em especial ofereceria elementos para entender como o ensino de Filosofia é pronunciado nos discursos "oficiais". Fizemos, assim, um exercício analítico na esteira do que Agamben (2009) define como contemporaneidade, isto é, uma relação de afastamento do sujeito com o seu tempo, em que a tomada de consciência daquele sobre esse alavancaria uma atitude 
crítica e reflexiva.

Na esteira das descrições empreendidas, pode-se conjecturar que o projeto neoliberal, na grade de inteligibilidade que Ihe é própria, vem pautando muitas das discussões curriculares. Nesse sentido, o ensino da Filosofia, como componente de uma instituição que é, em termos althusserianos, aparelho de Estado, vem sendo transformado, nos seus arranjos curriculares, por certos enunciados e estratégias discursivas que vão de encontro a pressupostos imprescindíveis no saber filosófico. Por consequência, podemos concluir que um dos programas de luta do professor de Filosofia na contemporaneidade terá que ser conjurado na sala de aula, freando as investidas neoliberais que procuram dobrar o conhecimento da Filosofia às demandas imediatistas e utilitaristas da economia de mercado.

Entretanto, esse enfrentamento é um dos lados do combate. O outro, lastimavelmente, tem a ver com a ameaça (mais uma vez...) da retirada da Filosofia da Escola Básica, provavelmente isso acontecendo com maior vigor na Rede Pública de Ensino. Se, como acompanhamos, mesmo em períodos em que ela esteve calçada por dispositivos legais sua presença foi diluída negativamente nos currículos gaúchos, o que daria para esperar da época em que escrevemos este texto, cuja marca é a desobrigação de ofertar esse componente?

\section{Referências}

ABREU, Marisa. Lições do Rio Grande Referencial Curricular para as escolas estaduais. In: RIO GRANDE DO SUL. Lições do Rio Grande: Ciências Humanas e suas tecnologias. Referencial Curricular. Porto Alegre: Secretaria de Estado da Educação, 2009.

AGAMBEN, Giorgio. "O que é o Contemporâneo?" In: AGAMBEN, Giorgio. O que é o Contemporâneo? e outros ensaios. Chapecó, SC: Argos, 2009.

AQUINO, Julio Groppa. Educação pelo arquivo: ensinar, pesquisar, escrever com Foucault. São Paulo: Intermeios, 2019.

BATISTA, Bruno Nunes. Foucault e a genealogia do neoliberalismo. Movimento - Revista de Educação, Niterói/RJ, v. 6, n. 11, jul-dez. 2019.

BECK, Ulrich. Sociedade de risco: rumo a uma outra modernidade. São Paulo: Editora 34. 2010.

BRASIL. Base Nacional Comum Curricular: Educação é a base. Brasília, DF: Ministério da Educação, 2018.

COSTA, Sylvio Gadelha. Governamentalidade neoliberal, Teoria do Capital Humano e Empreendedorismo. Educação \& Realidade, Porto Alegre, vol. 34, n. 2, pp. 171-186, ago. 2009.

DERRIDA, Jacques. Mal de arquivo: uma impressão freudiana. Rio de Janeiro: Relume Dumará, 2001.

DURKHEIM, Emile. A evolução pedagógica. Porto Alegre: Artes Médicas, 1995.

ESTADO DO RIO GRANDE DO SUL. Lições do Rio Grande: Ciências Humanas e suas tecnologias. Referencial Curricular. Porto Alegre: Secretaria de Estado da Educação, 2009.

ESTADO DO RIO GRANDE DO SUL. Proposta pedagógica para o Ensino Médio Politécnico e Educação Profissional Integrada ao Ensino Médio. Porto Alegre: Secretaria de Estado da Educação, 2011. 
ESTADO DO RIO GRANDE DO SUL. Reestruturação curricular Ensino Fundamental e Médio. Porto Alegre: Departamento Pedagógico da Secretaria de Estado da Educação, 2016.

ESTADO DO RIO GRANDE DO SUL. Referencial curricular gaúcho: Humanas. Departamento Pedagógico da Secretaria de Estado da Educação, 2018.

FOUCALT, Michel. Vigiar e punir: nascimento da prisão. Petrópolis, RJ: Vozes, 1987a.

FOUCAULT, Michel. A arqueologia do saber. Rio de Janeiro: Forense-Universitária, 1987b.

FOUCAULT, Michel. Ditos e escritos II: Arqueologia das ciências e histórias dos sistemas de pensamento. Rio de Janeiro: Forense Universitária, 2000.

FOUCAULT, Michel. Nascimento da biopolítica: curso dado no Collége de France (19781979). São Paulo: Martins Fontes, 2008.

GRAMSCI, Antonio. Cadernos do Cárcere, volume 2. Rio de Janeiro: Civilização Brasileira, 2001.

HARDT, Michael. A sociedade mundial de controle. In: ALLIEZ, E. (Org.). Gilles Deleuze: uma vida filosófica. 1. ed. São Paulo: Editora 34, 2000.

KANT, Immanuel. Crítica da razão pura. São Paulo: Abril Cultural, 1980.

LEITE, Lúcia. Pedagogia de Projetos: intervenção no presente. Belo Horizonte: Dimensão, 1996

NIETZSCHE, Friedrich. Genealogia da moral: uma polêmica. São Paulo: Companhia das Letras, 1998.

NOSELLA, Paolo. A escola de Gramsci. Porto Alegre: Artes Médicas, 1992.

SANTOS, Milton. A natureza do espaço: técnica e tempo, razão e emoção. São Paulo: Hucitec, 1996.

SENNET, Richard. A corrosão do caráter. Rio de Janeiro: Record, 2008.

VEIGA-NETO, Alfredo. Educação e governamentalidade neoliberal: novos dispositivos, novas subjetividades. In: PORTOCARRERO, Vera; CASTELO BRANCO, Guilherme.

(Orgs.). Retratos de Foucault. Rio de Janeiro: NAU, 2000.

\section{Correspondência}

Bruno Nunes Batista - Rua Almirante Barroso, 1202, Centro, CEP: 96010-280, Pelotas, Rio Grande do Sul, Brasil.

\section{(c) (1) (8)(2)}

This work is licensed under a Creative Commons Attribution-NonCommercial 4.0 International (CC BY-NC 4.0) 